\title{
Melilla: entre Oriente y Occidente
}

\author{
FEDERICO LARA PEINADO \\ Universidad Complutense. Madrid
}

La práctica totalidad de prehistoriadores e historiadores coinciden en señalar que las costas noroccidentales de Africa estuvieron desde los tiempos más remotos abiertas y abocadas a la Península Ibérica por razón de su situación geográfica y que, en consecuencia, el trasvase de poblaciones fue una cosa común a uno y otro lado del Estrecho de Gibraltar desde el más temprano Paleolítico.

Esto quiere decir que el estrecho que separa los continentes europeo y africano sirvió más para unir que para separar, siendo así un elemento comunicador de capital importancia histórica.

Si uno se detiene en la bibliografía especializada para intentar estudiar el desarrollo histórico de Melilla, observará que para las etapas prehistóricas el vacío es notable. Ello es, ante todo, consecuencia de la escasez de estudios sobre la Prehistoria de Africa del Norte, que de siempre han estado centrados en otros puntos del continente más que en Marruecos. 
Esa carencia significa que los conocimientos que se poseen de tan largo período histórico -en este caso, prehistórico- son muy elementales. Apenas conocemos unas generalidades, emitidas por autores franceses, como Biverson, acerca del Paleolítico Inferior, o como Balout, sobre el Musteriense del Magreb. Estos escasos estudios nos informan del poblamiento de aquellas etapas prehistóricas en la zona norteña africana, sin apenas aportar datos de interés. El Pelolítico Superior cuenta también, lamentablemente, con muy pocos estudios. Mejor es la visión del Epipaleolítico, gracias al trabajo de Roche, completado para la etapa neolítica por los estudios de Tarradell, Jodein y Souville, dedicados respectivamente al Neolítico occidental de Marruecos, a los problemas del Vaso campaniforme y a las influencias proyectadas desde la Península Ibérica sobre el último neolítico marroquí.

Como señaló Gozalbes Cravioto en 1980, en un trabajo publicado en los Cuadernos de la Biblioteca Española de Tetuán, se ignora en qué momento las costas del Rif Ilegaron a ser ocupadas, detectándose, sin embargo, la presencia humana en las mismas en tiempos imprecisos del Paleolítico, y en puntos muy concretos, que pueden ser seguidos en el mapa arqueológico que en 1933 elaboró Montalbán, mapa cuestionado por Tarradell, quien no llegó a aceptar ninguno de los yacimientos indicados en tal mapa como realmente antiguo.

En la región oriental del norte de Marruecos las exploraciones llevadas a cabo por Posac facilitaron información sobre algunos puntos, ubicados en la zona del río Yazanen o en Taxuda.

Por lo que respecta a Melilla hay constancia de algunos pequeños hallazgos prehistóricos, dados a conocer gracias a las referencias que en su momento - año 1907- dio el francés Pallary, quien durante un viaje, efectuado por tierras norteñas del oriente marroquí, aludió a unas cuantas piezas líticas, procedentes del material existente en la zona del Gurugú. Incluso aludió a huevos de avestruz.

De esas escuetas noticias se pasa, en un salto espectacular de milenios de duración, de los que nada sabemos, a la etapa púnica, cuando se supone que en el área de cabo de Tres Forcas, adelantado al mar, gentes venidas de Cádiz, según unos, de Ibiza y costas béticas, según otros, de Carta- 
go o de la propia Tiro para algunos más, caso de Gozalbes Cravioto, fundarían un enclave colonial, al que dieron el nombre de Rusadir.

Es de aceptación común la identificación de Rusadir con Melilla, no habiéndose cuestionado nunca tal identidad. Identidad que no sería especificada, por otra parte, hasta el siglo XVI, gracias al autor granadino Luis de Mármol y Carvajal, quien dijo de ella en su Descripción general de Afri$c a$ : "Melilla es muy antigua y los africanos la llamaban Deyrat Milila, mas según Ptolomeo se llamó Russadiro".

A finales del siglo pasado, los trabajos de Geografía comparada del francés Tissot certificaron la identificación de Rusadir con Melilla.

Tal enclave ha tenido su confirmación arqueológica, evidenciando así las referencias que en algunas fuentes clásicas se hacía del mismo. Fue con ocasión de la construcción de diferentes elementos arquitectónicos en 1904 cuando en el Cerro de San Lorenzo se hallaron diferentes ánforas que servirían para detectar poco después tres necrópolis —una púnica, otra romana y otra musulmana- que proporcionaron abundantes materiales y a cuya salvación y estudio contribuyó - como saben todos Vds.- el periodista y buen melillense Fernández de Castro, autor de diferentes trabajos sobre tales necrópolis.

Dado que a otros profesores y especialistas les ha sido encomendado el estudio monográfico de la atendicha necrópolis, de sus materiales y de otros aspectos conectados con la historia antigua de Melilla, declinamos el hacer referencia a los mismos y a tratar de interpretarlos. Personas con mayores conocimientos del tema que el que les habla darán cumplida información de los mismos.

Nuestra exposición va a centrarse, aunque sea superficialmente, en un examen de cuantos acontecimientos históricos merecen ser destacados de acuerdo con la historiografía que se ha ocupado de Melilla. Tales acontecimientos nos permitirán ver a Melilla como una ciudad con personalidad propia, a caballo entre Oriente y Occidente, dado que la propia ubicación de la misma - pensemos en el río Muluya como frontera en muchos momentos de la historia de estas tierras - la hizo desempeñar ese papel de ciudad abierta a muchas culturas. 
Podemos decir que hasta el siglo XV Melilla gravitó a impulsos de Oriente, aunque sin perder nunca su conexión ancestral con el sur de la Península Ibérica. A partir de aquel siglo - la fecha del 17 de septiembre de 1497 es clave- Melilla puede estudiarse en total identidad con Occidente.

El espectacular silencio - por su amplitud cronológica - al que antes hemos aludido y durante el cual la primitiva Melilla se sumió en total mutismo, se debe a la propia idiosincrasia de las fuentes orientales, nada explícitas en información a terceros, por razones ante todo de índoles religiosa y económica. En efecto, sabemos que a los puntos neurálgicos del antiguo Oriente hubo de llegar a través de los navegantes prospectores de metales, primero cretenses y micénicos, y luego Publos del Mar, noticias acerca de las riquezas mineras del Occidente mediterráneo, información que luego se evidenciaría con las riquezas aportadas directamente desde el área de Gadir a los puertos fenicios de Biblos, Sidón y Tiro, cuando sus marineros se habían atrevido hacia el 1100 a.C. a traspasar las míticas Columnas de Hércules.

Fueron los fenicios quienes en una espectacular política colonizadora sembraron todo el Mediterráneo de colonias y factorías, haciendo del mismo un verdadero mar interior, cohexionando así modos de producción, de economía y aún de cultura.

Desde Cartago, colonia fundada en el año 814 y convertida luego en verdadera ciudad imperial, llegaría a controlar la práctica totalidad de las costas africanas y de las sureñas de la Península lbérica durante más de 500 años, siendo su proyección todavía más espectacular al atreverse a efectuar sus marineros viajes de largo alcance, y por Hannón, poco después, al golfo de Guinea.

La expansión fenicia, en contra de lo que se ha venido afirmando, hubo de ser planificada con toda lógica, estableciendo las ciudades metrópoli sus colonias no de modo arbitrario, sino de acuerdo a una logística racional, que les posibilitase los sucesivos desplazamientos con todo tipo de seguridades, y en un proceso colonizador dirigido de Este a Oeste.

Muy probablemente, y también en contra de lo afirmado por el autor francés Julen y otros especialistas que postulan una fundación de Melilla en el siglo VIII a.C. directamente desde Tiro, creemos que fue en época púnica y algún tiempo después — siglos VII-VI a.C.- cuando se fundaría 
Rusadir, Melilla, cuyo topónimo equivalía en fenicio a "cabo imponente", en clara alusión al Cabo Tres Forcas. Dicha fundación se produjo a impulsos de los viajes emprendidos desde Gadir por toda las costas de Marruecos, tanto atlántida como mediterránea, alcanzando incluso las costas del oranesado argelino. Aquí se fundarían los enclaves de Rachgoun, excavado hace algunos años por $\mathrm{G}$. Vuillemot, quien dictaminó que podría tratarse de algún enclave de vigilancia costera, el de Mersa-Madakh, concebido como simple escala naútica, y Los Andalouses, de características difíciles de analizar dado lo exiguo del material arqueológico encontrado.

Podría admitirse que Rusadir pudo haber sido fundada en época púnica, pero directamente desde Cartago, durante la expedición de Hannón, llevada a cabo a partir del año 425 a.C. Tal navegante cartaginés iba provisto, como sabemos, de 60 pentecónteras y 30.000 hombres y mujeres, destinado todo ello, enseres y personas, a fundar colonias. Dado que últimamente se cuestiona el citado viaje, siguiendo las tesis que G. Germain expuso en 1957, por contener préstamos parciales de Herodoto y de otros autores, la narración del Periplo que nos ha llegado, debemos tomar con cautela esta posibilidad.

En cualquier caso coincide con la aportada en el llamado Pseudo Scylax, anónimo autor que en el siglo IV precristiano, remedando el famoso Periplo del matemático y geógrafo cario de igual nombre que había escrito otro Periplo hacia el 522 a.C. se lanzó a escribir un relato sobre las costas mediterráneas y adyacentes, teniendo a la vista una antigua descripción cartaginesa. A pesar de las interpolaciones y las imprecisiones algunos de sus pasajes son de sumo interés para evaluar la navegación que practicaban los cartagineses hasta el su del Marruecos atlántico.

Tal autor, en el fragmento 111, menciona una isla, el cabo Grande, la ciudad de Akros y su golfo, elementos que si bien son susceptibles de ser identificados con otros puntos costeros africanos, también se pueden adscribir al área de Melilla, aceptando la antiquísima tesis de Tissot (1877). En cualquier caso, para esta problemática debo aludir como referente acerca del estado de la cuestión a un trabajo del profesor Pastor Muñoz, que se ocupa de las fuentes literarias griegas y romanas referentes al norte de Marruecos, y a un reciente y documentado libro del doctor Gozalbes Cravioto. 
Llegado aquí cabe expresar la problemática que presenta la cita de Hecateo de Mileto, un geógrafo griego que vivió hacia el 500 a.C. y que en el fragmento de uno de sus escritos, recogido por Esteban de Bizancio, cita cuatro ciudades de Marruecos, siendo una de ellas Metagonium, que para Estrabón, otro geógrafo que vivió a finales del siglo I, también antes de Cristo, debía ser identificada con el Cabo Tres Forcas y consecuentemente con Melilla, enclave metagoniano situado, según puntualiza, "casi frente a frente de Carthagonova, al otro lado del mar". No obstante, Metagonium constituye uno de los problemas más serios de identificación, no pudiendo ser ubicada con exactitud en el estado actual de nuestros conocimientos, aunque por lo que se puede deducir del historiador Polibio, hubo de hallarse en el área de Rusadir, según opina dicho autor acerca de los preparativos de Aníbal cuando había decidido pasar a Iberia.

En cualquier caso, y fuese como fuese, la situación geográfica del lugar hizo que allí los púnicos fundasen primero un establecimiento de refugio y avituallamiento, que luego convertirían en un puerto-jalón en terminología del profesor López Pardo, mucho más operativo, y más tarde a la vista de la producción agrícola de sus alrededores y las menas de algunos metales del interior, ubicaron una colonia estable, cuyo auge debe ser situado, sin embargo, a partir del siglo III a.C., según han evidenciado los restos arqueológicos más antiguos, consistentes en una lucerna rodia y en un cuenco megarense, fechados en aquel siglo por los arqueólogos.

Los colonos y las gentes nativas quedaron incorporados a las estructuras cartaginesas dentro de tres estados vasallos: los maurisios, los maselisios y los masilios, los cuales pocas centurias después se verían obligados a luchar al lado de Gartago, con ocasión de las Guerras Púnicas, iniciadas en el 246 a.C. cuando Roma al llegar a Sicilia había chocado con los establecimientos cartagineses allí ubicados.

También, al lado de las gentes de Rusadir y de otras colonias africanas, habían tomado partido por Cartago, según nos informa Polibio, los celtíberos y otras gentes hispanas.

Después de dominar a los cartagineses, los romanos — según apuntó el historiador francés Terrase- no ocuparon de inmediato el norte de Africa occi- 
dental y central, dadas las desfavorables condiciones geográficas que a ojo de los nuevos amos reunían aquellas tierras, aunque ello no fue obstáculo de su presencia militar en el mundo indígena, claramente hostil a los dominadores, según han probado restos arqueológicos hallados en diferentes lugares.

Anexionada Cartago, su territorio fue convertido en la provincia Africa proconsular, manteniéndose el resto del Africa norteña bajo un discreto control militar. En época republicana romana se produjeron diferentes episodios con ocasión de la conquista de la Península Ibérica, a los cuales no haremos referencia para no sobrecargar esta exposición fáctica de acontecimientos. Sí diremos, en cambio, que el norte de Africa había reaccionado ante los nuevos conquistadores. De todos $\mathrm{Vds}$. es sabido que los lusitanos pasaron el Estrecho de Gibraltar y que Sertorio, en el año 80 a.G., había llegado a tomar Tingi, actualmente Tánger. Más tarde, con ocasión de las guerras civiles, tanto las tierras de lo que sería después Mauritania como las de Hispania tomaron partido por uno u otro de los bandos contendientes. En el año 25 a.C. Octavio Augusto, ya dueño único de Roma, organizó sus territorios, controlando personalmente Egipto, incorporando Numidia a Roma y dejando con algo de independencia a Mauritania, bajo el control de Juba II, siempre tutelado por Augusto.

En época del emperador Tiberio, los númidas al mando de Tacfarinas, se levantaron en armas contra Roma, rebelión a la que se pudo hacer frente gracias a la ayuda que el rey mauritano Ptolomeo, hijo de Jubal II, antes citado, y de Cleopatra de Selene, había prestado a Tiberio. No obstante, Ptolomeo sería asesinado poco tiempo después por orden del nuevo emperador Calígula. Este hecho motivó la sublevación de toda Mauritania y Numidia, cuyos habitantes, capitaneados por Eudemón, presentaron serios problemas a los romanos.

Tras no pocos esfuerzos Cayo Suetonio Paulino y Cneo Hosidio Geta controlaron la sublevación y llegaron a pasear las águilas romanas nada menos que hasta el río Guir, ya en el Sahara. Todos los territorios norteafricanos, desde el Atlántico hasta los confines del Mar Rojo, quedaron en el año 40 de nuestra era en poder romano. Sin embargo, en amplias zonas del interior -en nuestro caso, Aurés, el Rif y el Atlas- se mantuvo cierta insumisión, por parte de mauri -término derivado de Mauritania, con el 
significado de "lejano", y que daría nombre, aunque indebidamente, y con posterioridad, a los musulmanes en general-.

El territorio controlado por los romanos quedó dividido en dos provincias, la Mauritania Tingitana, con capital en Cesárea, esto es, Cherchel. La línea divisoria entre ambas provincias se fijó en el río Muluya, si bien sobre este particular los historiadores aún no se han puesto de acuerdo.

Dicha separación administrativa había tenido lugar en tiempos de Calígula, según unos, o en los de Claudio, hacia el año 46, según otros. Rusadir por su situación geográfica, lógicamente pasó a formar parte de la Mauritania Tingitana, manteniendo el estatuto de colonia, que le había otorgado el emperador Claudio, junto a otras ciudades mauritanas.

La importancia creciente de Rusadir quedó refrendada en las fuentes clásicas de carácter geográfico, entre ellas en los Chorographia $(\mathrm{I}, \overline{5})$ del gaditano Pomponio Mela, geógrafo del siglo I de nuestra era, quien cita el río Tamuda (el actual Martín en Tetuán) y los pequeños enclaves - parvas urbes- de Rusgada, a identificar con Rusadir, Siga, situado en Argelia, y un Gran Puerto, a identificar muy probablemente con la Mar Chica, en cuya área han aparecido hallazgos submarinos de ánforas romanas.

Asimismo, Plinio, en el libro $\mathrm{V}$ de su Naturalis Historia, recoge el topónimo Rhyssadir, al cual califica de oppidum, al igual que Caludio Ptolomeo, autor del siglo II, natural de Alejandría, quien en su obra geográfica (IV, 3), de consulta obligada nada menos que hasta el siglo XVI, recogió en su tablas la situación en coordenadas de varios accidentes geográficos del norte de Marruecos, así como a cuatro ciudades, Iagath, Acrat, Taenia Longa y Rusadir, prueba evidente de la existencia de este enclave en el siglo II.

Igualmente, en el llamado Itinerario Antonino, obra muy probablemente redactada durante el gobierno de Diocleciano, y que venía a ser una especie de mapa de los caminos romanos del siglo segundo de nuestra era, incluye la mención de Promontorium Russadir que sitúa a 50 millares de pasos de Tingi, y la de la Colonia Russadir. Un excelente trabajo de Euzennar, publicado en la revista Latomus, en 1962, aporta datos sobre el particular de las vías romanas de Marruecos, recogidas en el mencionado Itinerario. 
Años más tarde, según sabemos por la Historia Augusta, en unos pasajes relativos a la Vita Marci y a la Vita Severi, respectivamente, esto es, hacia el 162 o poco después, durante el gobierno del emperador Marco Aurelio, grandes áreas de la Mauritania se vieron envueltas en una serie de agitaciones promovidas por sus propios habitantes, los mauri, cuyas tribus, descendientes de paleobereberes, según unos, o bereberes sin más para otros, motivadas por las presiones fiscales y una gran carestía de víveres a causa de la escasez de agua, tras asolar los enclaves costeros y apropiarse de algunos barcos llegaron a pasar a Hispania y atacar a la Bética.

Para algunos especialistas - H. Pflaum, C. Castillo, entre ellos- hubo una sola invasión, a situar en el año 171. Otros piensan en dos invasiones, una la del 171 y otra en el 177, aduciendo para ello un pasaje de la Vita Marci, dos inscripciones de la Bética, una de Itálica y otra de Singilia Barbara. Por razones de contexto no podemos entrar en su análisis, pero nos remitimos a la tesis de Nieto Navarro para el particular.

En cualquier caso, la invasión de mauri en territorio peninsular significó serios problemas que sólo se resolvieron con la venida a Hispania en tropas romanas desde Macedonia y con la pericia del legado Caio Aufidio Victorino, que pudo cortar el primer envite en el 173. La segunda invasión, que al parecer se redujo a una razzia en la actual provincia de Málaga, y conocida por las inscripciones antes aludidas, fue repelida por el procurador de la Lusitania y también de la Mauritania Tingitana, Vallio Maximino, quien fue capaz de controlar la situación y replegar a los mauri hasta la propia Mauritania, hecho demostrable por la inscripción que la ciudad de Volubilis dedicó a tal personaje.

Estas sublevaciones eran reflejo de otras, suscitadas en las lejanas áreas del Danubio y de Oriente, reveladoras de la aguda crisis militar que se había originado en Roma con los últimos emperadores antoninos.

Tiempo después, y de acuerdo con la llamada Lista de Verona, redactada en el 297, Mauritania fue incluida en la nueva administración dada por Diocleciano, a finales del siglo III. Según dicha Lista, la Diócesis de las Hispanias contaría con siete provincias. Una de ellas fue la Mauritania a la 
Diócesis peninsular y la desconectaba del resto de Africa. La misma adscripción se repetiría con la reforma administrativa de Constantino.

Llegados a este punto deberíamos hacer una alusión al Cristianismo primitivo de Rusadir. De acuerdo con la heurística efectuada hay que indicar que es muy poco lo que se conoce acerca de la nueva religión que llegaría a Rusadir no desde la propia Africa - tesis ya descartada a partir de los estudios de M. Sotomayor hará unos diez años-, sino desde la propia Península.

A finales del siglo II ya existían cristianos en Mauritania, si hemos de hacer caso a Tertuliano, aunque todavía no se habían organizado en comunidades. Hay que argumentar que en el tiempo de Constantino se organizaría en Rusadir un obispado cristiano. Tampoco ha llegado, que sepamos, ningún elemento de aquella etapa, si bien Fernández de Castro dio la noticia de la existencia de una lucerna decorada con temática cristiana.

Un nuevo período histórico se iba a producir como consecuencia del testamento del emperador Teodosio. Según el mismo, los territorios africanos de Mauritania, junto con Numidia, el Africa proconsular, Bizacena y Tripolitana quedaron incorporados al Imperio romano de Occidente; el resto, esto es, Cirenaica y Egipto, al de Oriente. Corría el año 395 poco más o menos.

Si Roma había obtenido grandes recursos cerealísticos de Africa, la misma riqueza agrícola despertó también la codicia de los pueblos bárbaros que habían laminado al Imperio Romano. Incluso en el año 410, el propio Alarico I se había planteado la posibilidad de invadir Africa, lo que no pudo llevar a cabo a causa de su muerte. Su sucesor, Ataulfo, prefirió dirigirse a la Galia Narbonense y luego a Hispania en vez de a Africa, debiéndose enfrentar en tierras hispanas a otros pueblos germanos, suevos, vándalos y alanos, establecidos en ellas poco tiempo antes.

El rey Valia, que había pactado con Roma, logró derrotar a los alanos y vándalos silingos, pero ambos pueblos, a los que se habían unido los vándalos asdingos, fueron capaces bajo el mando de Gunderico de llegar en el año 420 a la Bética y embarcando en Cartagena someter a las islas Baleares a todo tipo de saqueos.

Debido a una serie de circunstancias políticas de carácter general y a hechos puntuales de tipo personal, fijados en la persona del conde Bonifa- 
cio, gobernador del Africa romana, que se había enemistado con Gala Placidia, madre del emperador Valentiniano III -el vencedor de Atila en los Campos Catalaúnicos-, y cuya exposición resultaría aquí prolija y totalmente tangencial al tema que nos ocupa, el decurso histórico nos hace conocer a Genserico, hermano bastardo del rey Gunderico, quien había pactado con el tal Bonifacio el acceso a Mauritania a cambio de su ayuda.

En cumplimiento del mismo, en el año 429, Genserico desde Tarifa, la Iulia Traducta romana, y al frente de todo su pueblo, evaluado en unas 80.000 personas, cruzó el Estrecho de Gibraltar y alcanzó las costas africanas. Desde Ceuta pasó a sangre y fuego a buen número de poblaciones del Africa norteña en su camino hacia Cartago, entre ellas Rusadir.

No todos los autores, siguiendo la tesis de Schmidt, planteada ya a finales del siglo pasado, aceptan como motivo del paso a Africa de los vándalos el acuerdo pactado con Bonifacio, sino simplemente a la situación de la defensa precaria que allí presentaban los romanos y a la posiblidad de un rápido acopio de víveres. En cualquier caso, el hecho histórico recoge la presencia de los vándalos, quienes sin encontrar resistencia pudieron adueñarse de toda Mauritania, Numidia y buena parte del Africa proconsular.

A cambio de un tributo anual de trigo, pactado en el año 435 con los romanos, que no tenían capacidad operativa en Mauritania, luego de ser derrotados en Hipona, Genserico conservó bajo su control prácticamente a la totalidad del Africa del norte, hecho sancionado definitivamente en el año 442 al firmar Valentiniano III un nuevo tratado con los vándalos.

A partir de entonces, los vándalos vinieron a desempeñar en Africa el papel que antaño había correspondido a los cartagineses. Situados los mismo en Cartago, el resto del norte de Africa fue confiado al control de jefes locales indígenas, quienes colaboraron en no pocas correrías de los dominadores, llevadas a cabo por todo el Mediterráneo occidental. Baleares, Córcega y Cerdeña cayeron en sus manos.

En el colmo del cinismo el propio Genserico en el 455 saqueó Roma, erigiéndose en vengador del asesinato de Valentiniano III. Con este emperador se había cancelado la dinastía de Teodosio en Occidente y se aceleraba el fin del Imperio. 
Desaparecido a su vez Genserico, el dominio vándalo desapareció del norte de Africa. También Roma había caido en manos de Teodorico, un rey de los ostrogodos.

Rusadir hubo de vivir entonces de modo autárquico, si bien fue convocado su obispo en el 477 a participar en el concilio a celebrar en Cartago. Salvo esta escueta noticia no se sabe nada de la Rusadir del siglo V.

Frente a esta zona occidental del Imperio Romano, el de Oriente había conseguido mantenerse, si bien a cambio de perder prácticamente todas sus señas de romanidad. Había dado paso al Imperio Bizantino, cuya época de máximo explendor se alcanzaría con el emperador Justiniano I (527-561), quien se aprestó, sintiéndose heredero de la Historia, a la tarea de la reconstrucción imperial.

Sabemos que para ello inició la reconquista de los territorios dominados por los vándalos. Buscando un casus belli, pudo enviar un ejéricto de 15.000 hombres a las costas africanas al mando del general Belisario, quien desembarcando no lejos de Cartago pudo vencer primero en tres encuentros y luego en Tricamerón en el 533 a los vándalos. Africa pasaba así al Imperio de Bizancio.

Rusadir, en consecuencia, pasaba a manos de Belisario quien se aprestaba a reconstruirla, dada la bondad de la situación geográfica de la misma.

En cualquier caso, esta hipótesis tiene su base en el hecho de que su nombre aparece como sede de un obispado cristiano en el llamado Thronus Alexandrinus, de comienzos del siglo VII.

Años después, en el 614, la ciudad fue conquistada, muy probablemente, por el rey visigodo Sisebuto, en una acción militar dirigida por Suintila que al tiempo que significaba la expulsión de los bizantinos le deparaba otros enclaves en la región del Rif.

En un corto período de tiempo, en el que las fuentes históricas sobre Rusadir permanecen mudas, el panorama político había cambiado considerablemente en el ámbito mediterráneo. Egipto en el 619 había caido en manos del persa Cosroes II. En Arabia, un personaje de La Meca, Mahoma, había comenzado la predicación de una sumisión absoluta - Islama un Dios único, y cuyo éxito motivó que los árabes en su mayoría acepta- 
ra sus doctrinas. A la muerte de tal profeta, en el 632, los dirigentes de la nueva religión, sobre todo los califas omeyas de Damasco, impusieron por las armas, dadas las condiciones de decadencia política de Bizancio, los preceptos predicados por Mahoma desde el Indo hasta el Atlántico.

Tras penetrar un pequeño contingente de árabes, mandados por Amrú ben al-Así, en Egipto en el 640, y en el 643 en Libia, muy pronto; en el 700, Muza ben Nusair alcanzaría Rusadir, ganándola para el Islam.

Por aquel entonces Melilla formaba parte, según Gozalbes Cravioto, del reino de Nakur, una ciudad del valle de Alhucemas, en donde tenían su asiento los Bau Salih. Sin embargo, faltan datos para asegurar que Rusadir quedase englobada en tal reino.

Es más, tampoco se puede afirmar que Rusadir continuase existiendo a mediados del siglo IX, y caso de haber existido realmente habría sido desvastada por los normandos con ocasión del ataque a que sometieron el norte de Africa en el año 859.

En un momento impreciso de finales del siglo IX fue cuando la antigua Rusadir púnica cambió su nombre por el de Melilla o Amlil, nombre que según un famoso gramático árabe, llamado en su conversión Juan León el Africano - y del que nos ocuparemos- equivaldría a "miel" o "melosa", circunstancia coincidente con la rica apicultura de la comarca, ya reflejada, por otro lado, en las monedas acuñadas en su ceca. Ejemplo de ello lo testimonian dos monedas. Una de ellas, hoy en el Gabinete Real de Numismática de Copenhague, procedente de Cherchel, capital que fue de Juba II, y otra hallada por Pelayo Quintero en Tamuda. Ambas representan en su reverso una abeja, en clara alusión a la riqueza en miel de Rusadir, con las leyendas RSADR y RSA, respectivamente.

No obstante, sobre la etimología del vocablo Melilla no se ha dicho todavía la última palabra. Hay quienes hacen del mismo el significado de "discordia", "fiebre" e incluso lo derivan del nombre de un personaje árabe.

En cualquier caso, fue en el siglo IX - hacia el 890- cuando nació Melilla, al ser ocupada por gentes bereberes el espacio ya abandonado de la Rusadir precedente. Entonces se le dio el nuevo nombre de Malila. 
Llegado aquí les ruego me permitan hacer un pequeño excursus en conexión con la problemática de los bereberes. Todos ustedes saben que tales gentes, distribuidas en diferentes tribus, habían ocupado el Africa septentrional desde tiempo prehistóricos.

Acerca de los mismos muchos prehistoriadores e historiadores se han planteado no pocos interrogantes; algunos resueltos, otros todavía a nivel de hipótesis. ¿Quiénes eran? ¿Conocieron la Edad de los metales? ¿Cómo pasaron de la barbarie a la civilización? ¿Conocieron la agricultura a través de los fenicios? ¿Por qué no se amoldaron a las estructuras romanas? ¿Tuvieron conciencia de su unidad étnica y lingüística? ¿Fueron islamizados o arabizados? Como ven, numerosos interrogantes a los que se les ha tratado de buscar solución.

En cualquier caso, los mapas étnicos que se han elaborado sitúan la zona del Rif como área ocupada por los bereberes. Allí vivieron y están viviendo gentes que ni fueron púnicos, latinos, vándalos, bizantinos, árabes, turcos ni europeos. Gentes capaces de dar un golpe de mano en el año 710 contra el sur de España al mando de Tarif ben Malluk, golpe que posibilitaría, al cabo de un año, el ataque más serio, dirigido por Tariq ben Ziyad, un bereber, probablemente zenete. La caída del rey visigodo Rodrigo el 19 de julio del año 711 significaría el fin de la monarquía visigoda, la entrada de bereberes en España, hecho que habría de cambiar el curso de la historia de la Península Ibérica.

Gracias a los historiadores árabes conocemos el catálogo de tribus bereberes, arabizadas o no, que se establecieron en Andalucía y que colaboraron con la construcción del Emirato independiente de Córdoba.

No podemos detenernos en el estudio de tales tribus, ni en sus orígenes, ni siquiera en su origen étnico, asociado al nombre de Mechta el-Arbi. A sus descendientes se les asociarían hacia el año 8000 a.C. los portadores de la cultura Capsiense, venidos de Oriente y conectados directa o indirectamente con la cultura natufiense de Palestina.

Este largo excursus acerca de las gentes que hubieron de habitar la Melilla prehistórica y neolítica se ha traido a colación ante la noticia, difundida por la prensa, todavía no hace un mes, de que el profesor Jorge Alonso 
había dado con la clave para traducir la lengua etrusca, emparentándola con el vasco, afirmando que las dos —el etrusco y el vasco- fueron introducidas en la Península y en el resto de Europa por el norte de Africa. Tal experto hacía hincapié, según la prensa, en que las lenguas prerromanas peninsulares y las bereberes del norte de Africa estaban interrelacionadas y poco menos que provenían del tronco común bereber.

Aceptando la posibilidad de que el etrusco se pueda interpretar a través del vasco, dado el carácter aglutinante de ambas lenguas, lo que ya resulta exagerado es la afirmación de que muchos idiomas - y cita la nota de prensa a los pueblos ibéricos, tartésicos, vascos, guanches; oscos, etruscos. cretenses, sumerios, hurritas, caucásicos- provengan del norte del continente africano, desde donde - dice Jorge Alonso- "emigraron tales pueblos en oleadas sucesivas a partir del sexto milenio antes de Cristo".

Pero volvamos al relato historico de Melilla.

Hacia el año 931 o quizá un poco antes, el primer califa de Córdoba, Abderramán III, volvió a ocupar Melilla, junto con Tánger y Ceuta, extendiendo su poderío sobre algunas tribus indígenas del interior, pero la ofensiva fatimí de los años 958-959 le hizo replegarse a las tres plazas indicadas, tras haber sido saqueadas.

Durante el siglo XI, Melilla fue ocupada por la tribu bereber de los Beni Urtedi quienes, gobernando de modo independiente en la misma, lograron darle cierta prosperidad, aumentando la producción de cereales y la explotación del hierro de Bani Said. Sin embargo, aquella prosperidad desapareció muy poco después, pues a partir de 1067 la ciudad se vería envuelta indirectamente en el proceso de desintegración política que se vivía en Al-Andalus con la existencia de los Reinos de Taifas. En Melilla se creó un reino idrisita de corta duración para sevir más tarde de escenario a los enfrentamientos de almorávides y almohades. En $1142 \mathrm{el}$ almohade Abd-Al-Mumin —según el profesor francés Rézete- saqueaba la ciudad, obteniendo de ella un cuantioso botín. Poco después, hacia el 1147, se proclamaba califa, al tiempo que destruía el poder almorávide con las capturas de Fez y de Marrakech. Tal personaje ganó a su causa a la España musulmana. 
En 1204 el califa almohade Al-Nasir, sucesor de Abu Yusuf Yaqub, el vencedor de Alfonso VIII en la batalla de Alarcos, preocupado por la defensa de sus territorios marroquíes pasó a fortificar fuertemente a Melilla. Tras los gobiernos de nuevos soberanos bereberes, cuya actividad sobre Melilla se ignora, en 1269 - tal vez antes- el territorio de Marruecos pasó a poder de los benimerines, otra dinastía bereber, originaria de las altiplanicies del interior de Marruecos, que se mantuvo en el poder hasta la mitad del siglo XV. Los dirigía Abu Yusuf Yaqub, quien incluso fue capaz de ocupar algunas plazas del sur de España.

Durante estos años Melilla, sin embargo, conoció una gran prosperidad material, gracias a su agricultura, sus colmenas, sus minas de hierro y la pesca de ostras perlíferas, sin olvidar sus contactos comerciales, establecidos incluso con los catalanes, según recoge documentación del siglo XIII.

Según algunos historiadores locales, entre ellos Mir Berlanga, los habitantes de Melilla cansados de las continuas disputas entre los reyes de Fez y de Tlemecén, cuyas consecuencias las pagaban directamente los melillenses, optaron en 1382 por abandonar sus casas al tiempo que destruían la ciudad. Según otras fuentes, fueron los reyes de Fez y de Tlemecén, que consideraban a Melilla como cosa propia, los que puestos de acuerdo dicidieron demolerla. Así se consigna en la Crónica de Pedro de Medina, cronista de la casa de Medina Sidonia, redactada en 1571.

Llegados a este punto, creemos que la historia antigua y medieval de Melilla, siempre a remolque de las influencias orientales y orientalizantes -púnicos, bizantinos, árabes- dejó atrás su pasado. A partir de año 1497 se abrió un nuevo período en la historia de la ciudad, ya incardinada plenamente en la historia de España y cuya continuidad, interrumpida durante estos 500 años ha hecho de la historia melillense una página más de la cultura occidental.

Todos ustedes conocen las vicisitudes de la toma de Melilla por parte de las tropas españolas dirigidas por el caballero de la casa ducal de Medina Sidonia, don Pedro de Estopiñán Virués, las cuales hallándola despoblada procedieron de inmediato a su reconstrucción aprovechando, según narran Pedro de Barantes y Pedro de Medina, historiadores del siglo XVI, los res- 
tos que allí existían. La ocupación fue un tanto novelesca, pues consistió en la rápida construcción de unos muros de madera durante la noche posterior al desembarco, los cuales pasaron como de piedra a los ojos de los moros. Parece ser que este tipo de fortalezas prefabricadas, según Rumeu de Armas, fue inventado por el maestro de artillería de los Reyes Católicos, de nombre Ramírez de Madrid.

No es el momento de pormenorizar aquí los intereses del conde de Medina Sidonia Juan de Guzmán, ni las acciones del comendador Martín Galindo o los reconocimientos preliminares del maestro artillero Ramiro López ni la expedición del propio Pedro de Estopiñán, quien al frente de 5.000 infantes, algunos caballos y unas cuantas piezas de artillería, amén de las maderas para los falsos muros, salido con unas naves del puerto de Sanlúcar de Barrameda, pudo tomar la plaza, sin derramar sangre, al rey de Fez, Muley Mohamed El Oataci.

Un texto interesante y que viene a corroborar que la ciudad de Melilla se hallaba vacía cuando arribó a ella don Pedro de Estopiñán es el contenido en la obra Descripción de Africa y de las cosas notables que en ella se encuentran, del famosos gramático árabe (nacido en Granada hacia 1487) Hasan ben Moh el Uazzan, personaje ya citado anteriormente y de agitada vida, quien capturado por los corsarios sicilianos había acabado en Roma al servicio nada menos que del Papa León X.

Tal gramático que hubo que bautizarse con el nombre de Juan León Africano, aunque luego volvería a su fe al recluirse en Túnez, escribió la antedicha obra en la cual da algunos datos sobre la toma de Melilla. Según su versión, el rey de $\mathrm{Fez}$, ocupado en otros menesteres bélicos en el área de Tamesa, al tener conocimiento por parte de los melillenses de que iban a ser atacados por los cristianos, tan sólo les pudo socorrer con un pequeño ejéricto. Al saber el abultado número de tropas que venían de España ignoramos cómo los nativos de Melilla habrían podido tener conocimiento de este particular - los melillenses optaron por evacuar la ciudad. Las tropas del rey de $\mathrm{Fez}$, ofendidas por este agravio, para vengarse de los melillenses huidos — quizás mejor para no dejar nada de provecho a los cristianos- pusieron fuego a la ciudad. 
Este mismo relato sobre la conquista de Melilla nos lo transmitió el viajero Luis de Mármol y Carvajal quien en el siglo XVI utilizó información marroquí. Por su parte, Gozalbes Cravioto en su estudio sobre la Melilla musulmana aporta dos nuevas versiones sobre el asunto, facilitadas en su día por Lorenzo Padilla y Pedro de Medina. Ambos autores coinciden en señalar que en el momento de la conquista Melilla estaba abandonada y destruida.

Gozalbes Cravioto señala que los indígenas pronto intentaron expulsar a los españoles, reaccionando en consecuencia el jefe de la región de Betoya, que controlaba la costa. Sus esfuerzos fueron inútiles, pues no pudieron hacer nada ante unos profesionales, ejercitados en las mesnadas del Duque de Medina Sidonia con ocasión de la reciente Guerra de Granada. En la batalla subsiguiente el jefe de Betoya halló la muerte.

En el rápido esbozo histórico que acabamos de efectuar se ha visto claramente la incidencia de dos grandes civilizaciones en el Africa norteña y en particular en Melilla: la occidental, que se posibilitó desde España, y la Oriental, aportada por el sustrato bereber y la posterior civilización musulmana.

Debe remarcarse, con todo, que el esbozo ha sido efectuado manejando únicamente historiografía occidental, cuya argumentación siempre ha descansado en las fuentes grecolatinas, muchas veces tendenciosas por ejemplificar modelos y paradigmas sociales.

Nada sabemos, por otro lado, de la específica historia bereber y por tanto nada podemos objetivar de los pueblos nativos del área que nos ha ocupado.

Melilla, y por extensión todo el Magreb - por utilizar la etiqueta del historiador A. Laroui- no debe verse como una zona conflictiva entre entidades y conceptos que nunca han sido bien definidos: Oriente y Occidente, Cristianismo e Islam, lenguas árabes y romances, Colonialismo y liberalismo. Su definición ha estado siempre manipulada y muchísimas veces ha sido entendida como algo antitético. 
El contacto entre Oriente y Occidente en Melilla debe verse como un acontecer natural, como algo ocurrido por la propia mecánica del suceder histórico, en el que cada componente desempeñó su cometido de acuerdo con las leyes históricas. Otra cosa bien distinta son las manipulaciones de los historiadores.

Las grandes innovaciones neolíticas se produjeron, como es sabido, en el Próximo Oriente, en donde nacióla agricultura, la ciudad-estado y la escritura. De allí esas innovaciones arribaron directamente al norte de Africa. Por otro lado, las innovaciones de la Edad de los Metales, surgida también en el Creciente Fértil, llegaron al norte de Africa, pero esta vez dando un largo rodeo, pues se introdujeron a través de lo que entonces era lberia.

El norte de Africa - y por lo tanto buena parte del Magreb- conoció la acción colonial de distintas civilizaciones: ibérica por el oeste, itálica por el este y sahariano-nilótica por el sur. Ello ha motivado que toda la zona septentrional marroquí, que no ha sido por la serie de circunstancias y condicionantes históricos ni completamente africana ni enteramente mediterránea haya tenido que oscilar siglo tras siglo en busca de su destino, en busca de su propia identidad, Porque, ¿es lícito que lo occidental quede anulado? ¿Es preciso negar lo oriental?

En cualquier caso, y como apuntó el historiador A. Laroui hará unos tres años en un importante libro, el contacto entre las poblaciones sedentarias de las costas africanas y los navegantes fenicios no debe verse como un encuentro entre la barbarie y la civilización, sino entre sociedades agrarias en curso de evolución y sociedades urbanas comerciales. Aquella presencia fenicia influiría en la posterior formación de monarquías africanas tal vez creadas como reacción a las presiones foráneas, claramente colonizadoras. Más tarde, Roma abortaría todo intento unificador africano, dividiendo a sus gentes en diferentes provincias, con lo cual el norte de Africa retrocedió a tiempos protohistóricos, retornando al sistema tribal, que intentaría ser superado, aunque no siempre conseguido durante el período islámico.

En la actualidad, y al hilo del centenario que se celebra en este año, no debemos ver el binomio Oriente-Occidente como algo opuesto, sino como una suma positiva. 
ALONSO GARCIA. I.: "Sustrato bereber. hispano-romano y heloreo en el Norte de Africa". Aproximación n las culmuras mediterrimeas del Norte de Africa. Melilla. 1983.

AYACIIE: A.: Le Maroc: Bilan de la colonisation. París. 1956.

ВАІ,ОL'Т, І.: Próhisloire de I'Africa du Nord. París. 1955.

BALTA, P.: El gran Magreb. Desde la Independencia hasta el año 2000. Madrid, 1994.

BARRIO, J.: "Protohistoria melillense: fenicios y cartagineses". Aldaba " $^{\prime 5}, 1985$.

BERQIIE, J.: Magreb, Mistorie et Societés. París, 1974.

BL.AZQLITZ, J. M.: " ${ }^{\prime}$ a crisis del siglo III en llispania y Mauritania 'Tingiıun". Hispanio, 108,1968 .

BOUSQUET. G. H.: Le's Berberes (Hisloire el Institutions). París, 19:7?.

(arcolPINO, J.: Le Mame Anlique. París, 1943.

CASARIliGO, J. E.: El Periplo de Hammón de Cartago. Madrid. 194?.

CESAR MORAN, P.: Vias y poblaciones romanas en el norte de Marruecos. Madrid. 1946.

C.INTAS, P.: Contribution à l'élude de l'expansion carlhaginoise au Maroc. Paris, 1955.

COLR'TOIS, Cl.: Les vandales ef lafripue. París. 19:5.

DECRET. F. Jantar, M.: LAfrique du Nord rlans l'Antiquité. Des origines an V'e. siècle. P'arís. 1981.

FERNANDEZ DE CAS'TRO, R.: "Molilla y sus fortilicaciones en la primera mitad del siglo XVI". Africa, abril, 1931.

FERNANDEZ IDE CASII'RO, R.: Melilla prehispánica. Madrid, 1945.

G.ARC:IA BEL.I.IDO, A.: España y los rspañoles hace dos mil años. Maclrid. 1968.
GOMLZ JAEN, J.: "Elimología y significado del vocablo Melilla". Mauritania, 199, 1944.

GOZAIBES (:RAVIOTO. E.: "Melilla, ciudad musulmana". Actas del / Congr.

Hispano-Africano de las culturas Mediterrinea (1984). II. 198 ?.

GOZAI JBES (:RAVIOTO, E.: "El epílogo de la Melilla musulmana”. Astas del / Congr.

Ilispono-Africamo de las culluras Mediterráneas (1984). II. 1987.

GONZALBES C.RAVIOTO, l:.: "Economía de la ciudal antigua de Rusudir". Aldaba n" 5, 1987.

COZAI.BES (IRAVIOTO, E.: "Atlas arqueológien del Rif". Cuadernos de la Biblioleca Espminola de Tetuón, 21-22, 1980.

GOZALBES (.RAVIOTOO F.: La ciudad antigua de Rusndir. Aportaciones a la Mistorin de Melilla en la Antigüedad. Melilla. 1991.

(BSELI. S. Hisloire ancienne de I'Afripue dh Nord. París. 191+-1928. 8 vols.

IL.LIF.. A. A.: Ilistoire de IAfrique du Nord. París, 1966. 2 vols. 2" ed.

L.AROUII, A. Mistoria del Magreb. Desde los origenes hasta el despertar magrebi. Madrisl, 1994.

I FMARCHAND, P. (1)ir.): Allas Géopolitique du Moyen-Orient et du monde arobe. Tournai. 1994.

1.OPE\% PARDO, F.: Mauritnmia Tingitana. De mercado colonial púnico a provincia romana. Madrid, 1987.

LOPI:Z PARDO). F.: "Sobre la expansión feniciurpúnica en Marruecos. Algunas precisiones a la documentación arqueológira". Archino Español de Aryueologia, 63, 1990.

LOPEZ PARIOO. F.: "EI Periplo de Hannón y la expansión cartaginesa en el Africa occidental”. $V$ Jormadas de Arqueología Fenicio-Pínica (1990). Ibiza, 1991.

1.OPEZ, PARIDO. F.: " "Los enclaves fenicios en el Africa toroccidental: del modelo de las escalas 
naúticas al de colonización con implicaciones productivas". Gerión, 14, 1996.

MIR BERLANCA, F.: Melilla en los pasados siglos y otras historias. Madrid, 1977.

MONTALBAN, C. I.: Mapa arqueológico de la zona del Protectorado de España en Marruecos. Madrid, 1933.

MORAN, P.C. GUASTAVINO, G.: Vías y poblaciones romanas en el norte de Marruecos. Madrid, 1948.

NIETO NAVARRO, M.: "Las incursiones de los mauri en la Bética durante el reinado de Mareo Aurelio. Nuevo estado de la cuestión". Actos del 1 Congr: Hispanpo-1/fricano de las culluras mediterrúneas (1984), 1. 1987.

PASTOR MLÃOZ, M.: "EI Norte de Marruecos a través de las fuentes literarias griegas y latinas. Algunos problemas al respecto". Actas del I Congr: Hispano-Africano de las culluras medilerráneas (1954), I, 1987.

PERICOT, L.: Prehistoria de Marruecos. EI Paleolítico y el Epipaleolítico. Tetuán, 1953.

POSAC, C.: "Las perspectivas arqueológicas de Melilla". Aldaba n" 9, 1987.

REZETE, R.: Los enclanes españoles en Marruecos. Paris, 1976

SAEZ CAZORLA, J. M.: Atlas arqueológico de Melilla. Trápana, 2, 1988.
SANCIIEZ AIBORNOZ, C.: La España musulmana. Madrid. 1978. 2 vols.

SARO GANDARILLAS, F.: "Cien años de liallazgos arqueológicos en Melilla". Aldaba: 1 , 1983.

SCHMITT, P.: Le Maroc d'après la Geographie de Claude Ptolomée. Tours, 1973.

SCHUBART, II., ARTEACA, O.: "EI mundo de las colonias fenicias occidentales". Homennje a Luis Siret. (Cuevas de Almanzora, 1984). Sevilla, 1986.

TARRADELL, M.: "I a necrópolis púnico-mauritana del Cerro de San Lorenzo on Melilla". I Congreso Arqueológico de Marrnecos Español. Tetuán, 1954.

TARRADELLI, M.: Marnecos puinico. Tetuán, 1960.

TERRASE, H.: History of Morocco. Casablanca, 1952.

TRONCOSO, A.: Ceuta y Melilla. 20 siglos de España. Madrid, 1981, 2" ed.

VAN DON7FI, J. (Comp.): Istamic Desk Reference. Leidlen-Nueva York-Köln, 1994.

WAGNER, C. C.: "Gadir y los más antignos asentamientus fenicios al este del Estrecho". Actas del Congreso Internacional. El Estrecho de Gibrallar. 1988. 